\title{
Drone to Collect and Clean Debris from Canals and Rivers
}

\author{
Vyom Rajan Singh \\ Mechanical Engineering Department \\ Noida Institute of Engineering and Technology \\ Greater Noida, UP
}

\author{
Dr. Chandan Kumar \\ Mechanical Engineering Department \\ Noida Institute of Engineering and Technology \\ Greater Noida, UP
}

\begin{abstract}
More and more trash is being released in water everyday either by money hungry industries who cuts cost in proper waste disposal or a lazy person who is lazy enough to go for a dustbin.

This alarming situation has attracted the attention of authorities around the world. Everyone is going towards finding a solution for this problem.
\end{abstract}

Cleaning water bodies is not only resources intensive but also very dangerous. Large cleaning vessels are limited by their lack of flexibility, high initial and maintenance cost. So, we started towards the unmanned drone area for fabrication of a machine to collect and clean debris from canals and rivers. This machine is dubbed as "AQUA TRV (Trash Recovery Vehicle)".

It involves two pontoons like structures connected with aluminum channel and built with fiberglass. The two pontoons not only add stability but also helps direct the floating algae/trash to the designated location where it is picked up by moving platform and dumped in the storage area onboard. Also, a, 4-axis extendable arm fitted with custom scoop bucket and powered by $16 \mathrm{~kg}-\mathrm{cm}$ analog servos along with high torque motor to provide linear actuation on the load bearing arm is used. Six servo mounted precision ultrasonic sensors are used, data is sent to a microcontroller in order to map the environment making it a semi-autonomous system. Vehicle is controlled with a $2.4 \mathrm{GHz}$ radio remote control along with a first-person view video link, this feature in combination with semi-autonomous surrounding mapping system enables the operator to control Aqua TRV with precision and higher surrounding awareness.

Keywords: Drone, Semi-Autonomous, Communication, sensors, motors, system, Transceiver, EDF (Electronic Ducted Fan), Humanoid, waste, collection.

\section{I.INTRODUCTION}

Water drones is a very unsaturated concept in drone industry and opportunity of its applications are limitless, this means with some modifications, tweaks and accessories a wide range of uses opens up.

From water cleaning utilizing different methods for different types of waste to long GPS guided endurance, a long and optimized endurance time on the drone can be multifunctional. Main idea behind the drone is to improve what had already been done and add a few more innovations in order to make the technology more reliable, efficient and accessible.

In this research paper construction and working of a drone is discussed which operates on water surface in order to collect floating trash employing the use of various mechatronics techniques. The drone is connected with operator with solid $2.4 \mathrm{GHz} \mathrm{RF}$ transmitter and receiver system to get more than $1.2 \mathrm{~km}$ LOS range. To get a better idea of the drone whereabouts an FPV (first person view) camera system is used. All the data from onboard sensors regarding environment is processed by an Arduino microcontroller and sent over to the operator for driving assistance making the drone semi-autonomous.

\section{II.TECHNOLOGIES USED}

Arduino Uno: The Arduino Uno is an opensource microcontroller board based on the Microchip ATmega328P microcontroller and developed by Arduino.cc. The board is equipped with sets of digital and analog input/output (I/O) pins that may be interfaced to various expansion boards (shields) and other circuits. The board has 14 digital I/O pins (six capable of PWM output), 6 analog I/O pins, and is programmable with the Arduino IDE (Integrated Development Environment), via a type B USB cable. It can be powered by the USB cable or by an external 9-volt battery, though it accepts voltages between 7 and 20 volts.

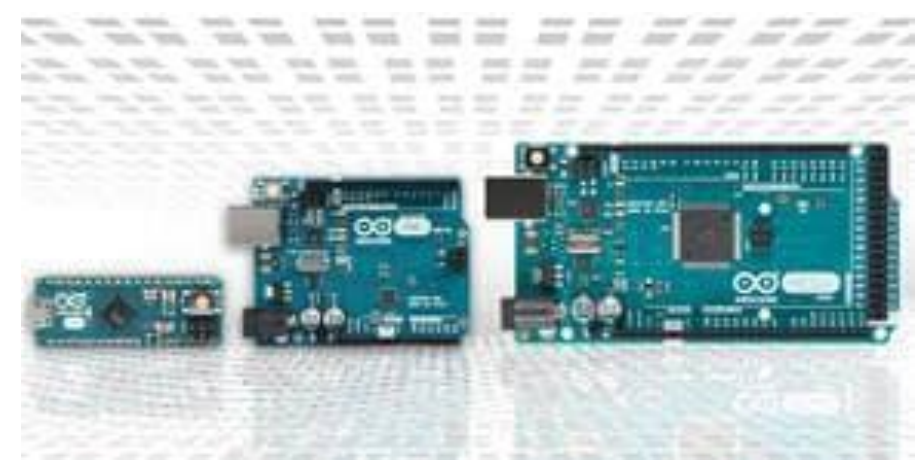

Modified EDF: A ducted fan is an air moving arrangement whereby a mechanical fan, which is a type of propeller, is mounted within a cylindrical shroud or duct. The duct reduces losses in thrust from the tips of the propeller blades and varying the cross-section of the duct allows the designer to advantageously affect the velocity and pressure of the airflow according to Bernoulli's principle. Although it is a concept applied in planes, some of its designing concepts are very useful in this case. With tweaks and modifications, 


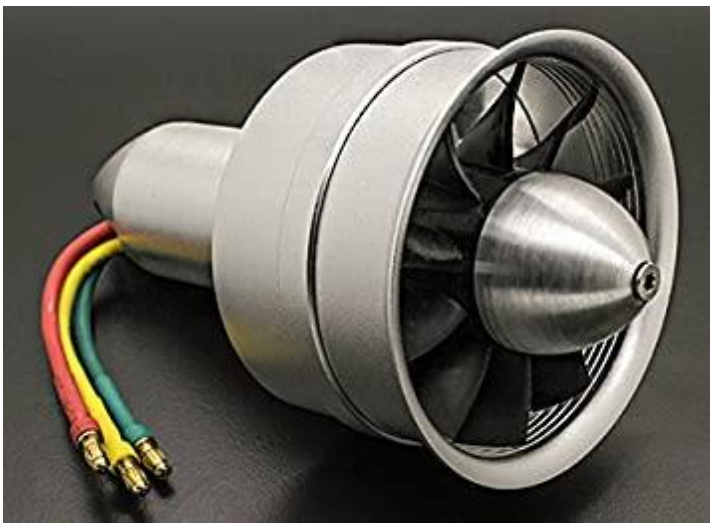

Some advantages include:

1. Ducted fans can allow for a limited amount of thrust vectoring, something normal propellers are not well suited for.

2. Ducted fans offer enhanced safety

3. By reducing propeller blade tip losses, the ducted fan is more efficient in producing thrust than a conventional propeller of similar diameter, especially at low speed and high static thrust level

Modification include upgrading and preparing it for underwater operation,

1. Adjusting the inlet angle in order to integrate it into drone's hull.

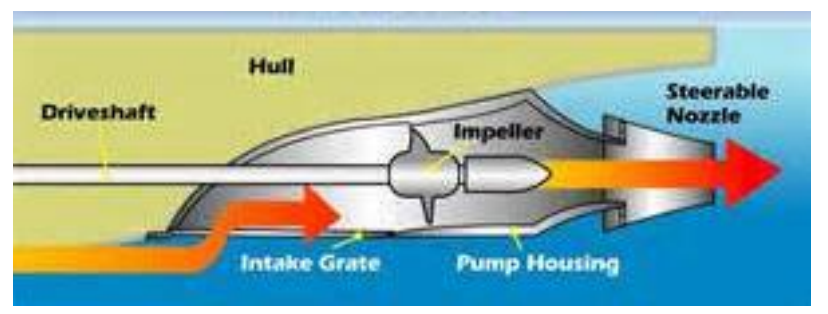

2. Adding net on inlet in order to prevent trash from entering the duct.

3. Adding atmospheric connection on the duct so, in case inlet does gets clogged propeller can use air to propel itself to shore.

Humanoid arm: (in jointed arm configuration) The jointed-arm robot is pictured in Fig. Its configuration is similar to that of the human arm. It consists of two straight components. Corresponding to the human forearm and upper arm, mounted on a vertical pedestal. These components are connected by two rotary joints corresponding to the shoulder and elbow.

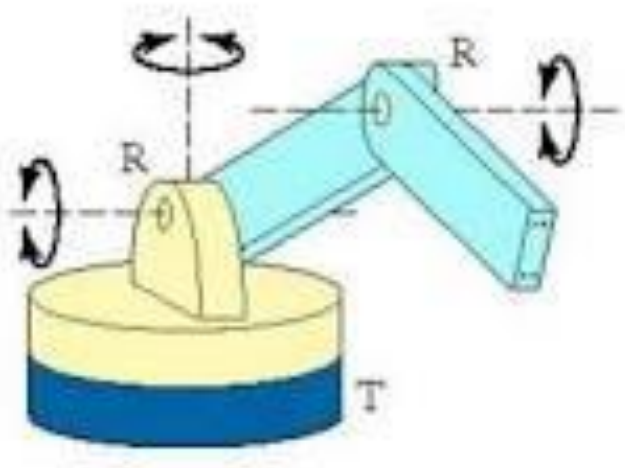

Configuration include the utilization of heavy-duty metal gear servos in joints, these servos have a torque of upto 2.70 $\mathrm{Kg}-\mathrm{cm}$. base rotating joint along with upper joint and claw are controlled by these servo motors but even with bigger and more powerful metal gear servo motor main pivot joint in the base controlling the whole weight of the arm is not enough. so, as a modification a linear actuator is used acting between two hinges, one hinge is connected to lower arm and another hinge is

connected to the base.

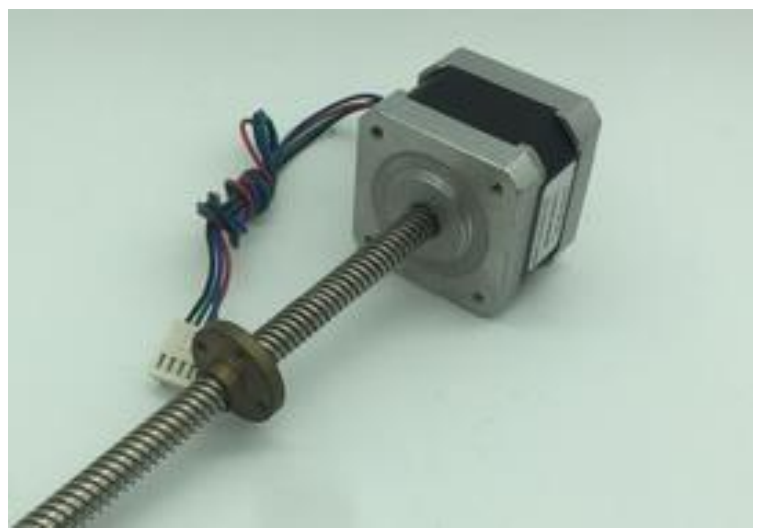

All four, metal gear servo motor and DC motor are controlled using Arduino and powered via a power distribution system.

Power to all the motors depend on the load on arm but voltage remains set for metal gear servo motors $(5.4 \mathrm{v})$, but for the dc motor (Fig 3) due to practical reasons like friction and unstable starting torque voltage is regulated using a suitable circuit. In order to determine position and regulate the output of said DC motor a proximity sensor is used. In order to reverse direction of the motor Arduino uses a $\mathrm{H}$ bridge. 


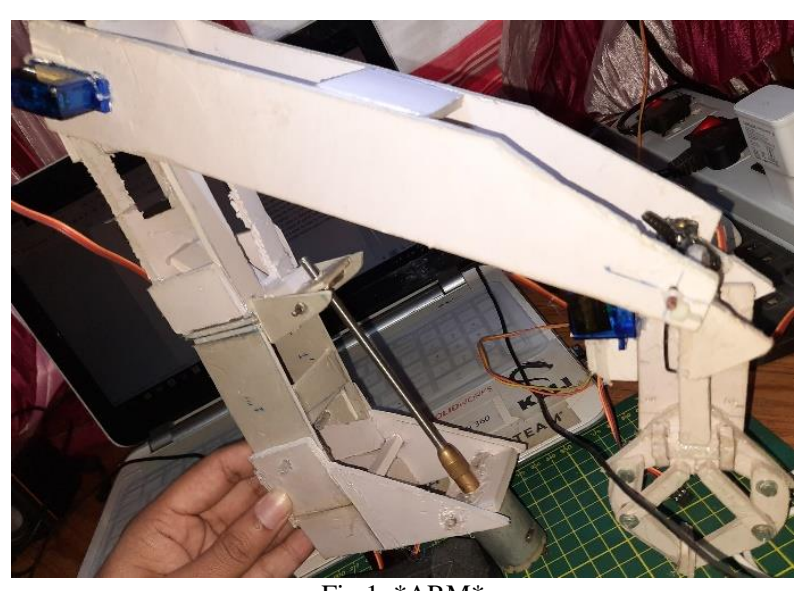

Fig 1. *ARM*

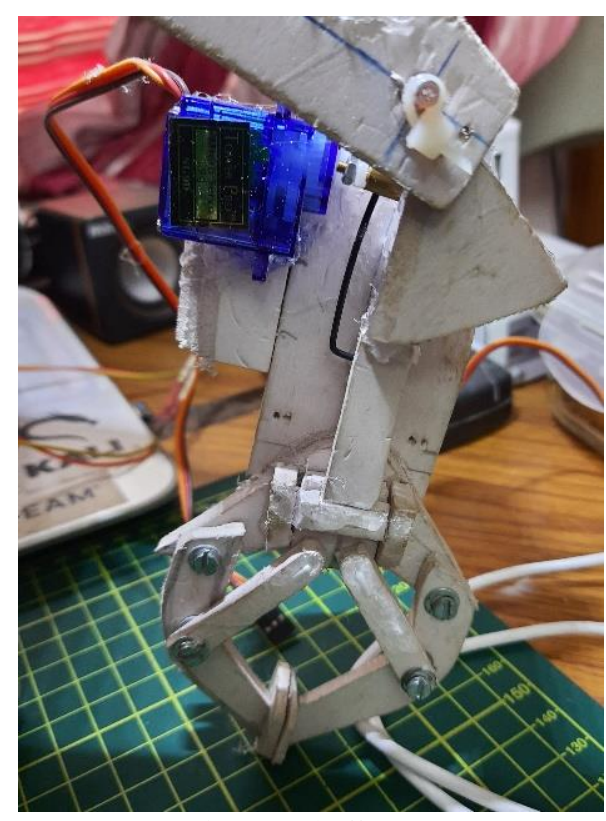

Fig 2. *End Effector*

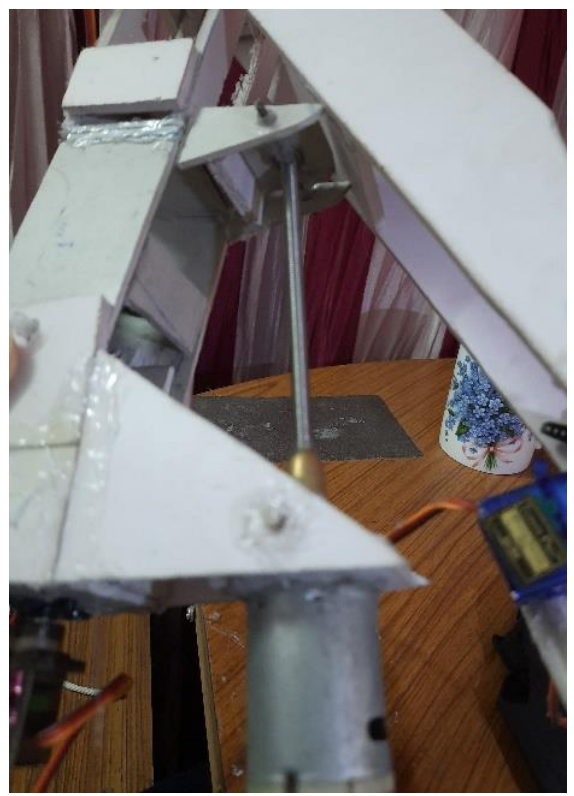

Fig 3. *Threaded rod Linear actuator*
FPV system: First-person view (FPV), also known as remote-person view (RPV), or simply video piloting, is a method used to control a radio-controlled vehicle from the driver or pilot's view point. Most commonly it is used to pilot a radio-controlled drone or other type of unmanned aerial vehicle (UAV). The vehicle is either driven or piloted remotely from a first-person perspective via an onboard camera, fed wirelessly to video FPV goggles or a video monitor. More sophisticated setups include a pan-andtilt gimbaled camera controlled by a gyroscope sensor in the pilot's goggles and with dual onboard cameras, enabling a true stereoscopic view.

There are two primary components of an FPV setup: the airborne component and the ground component (typically called a ground station). A basic FPV system consists of a camera and an analogue video transmitter on the aircraft with a video receiver and a display on the ground.

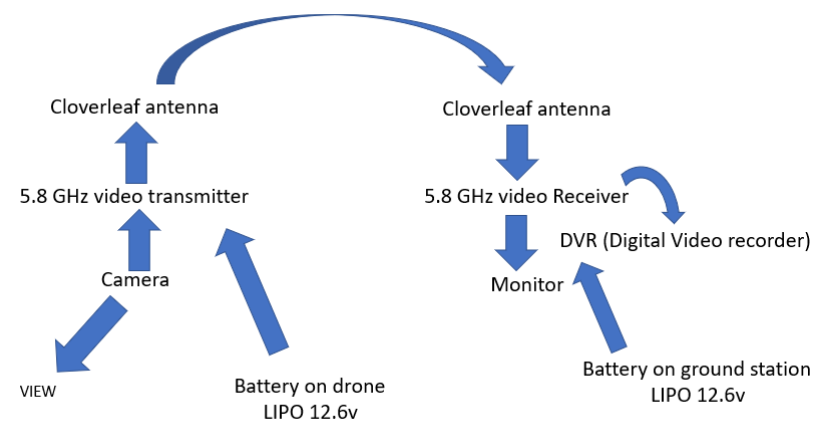

*FPV system flow chart*

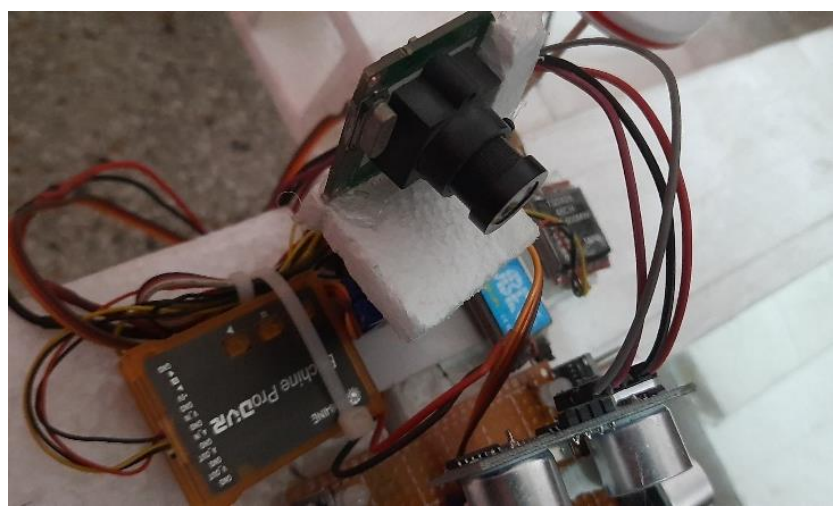

Fig 4. *FPV mounted system*

Thrust Vectoring: Thrust vectoring, also thrust vector control or TVC, is the ability of a vehicle to manipulate the direction of the thrust from its engine(s) or motor(s) to control the attitude or angular velocity of the vehicle. So, in other words thrust vectoring is used to control the orientation of body in space (under some constraints). Traditionally used on rockets and planes thrust vectoring nozzle is placed far back on the neutral axis of the vehicle, the nozzle itself can be controlled using carious means to tilt in both $\mathrm{x}$ and $\mathrm{y}$ direction.

Since, center of mass is far up and nozzle is down the neutral axis, any change in nozzle pointing direction can bring about change nose and the direction it is pointing.so, this means when nozzle is tilted to one side vehicle due to 
the torque developed about center of mass vehicle will also change direction.

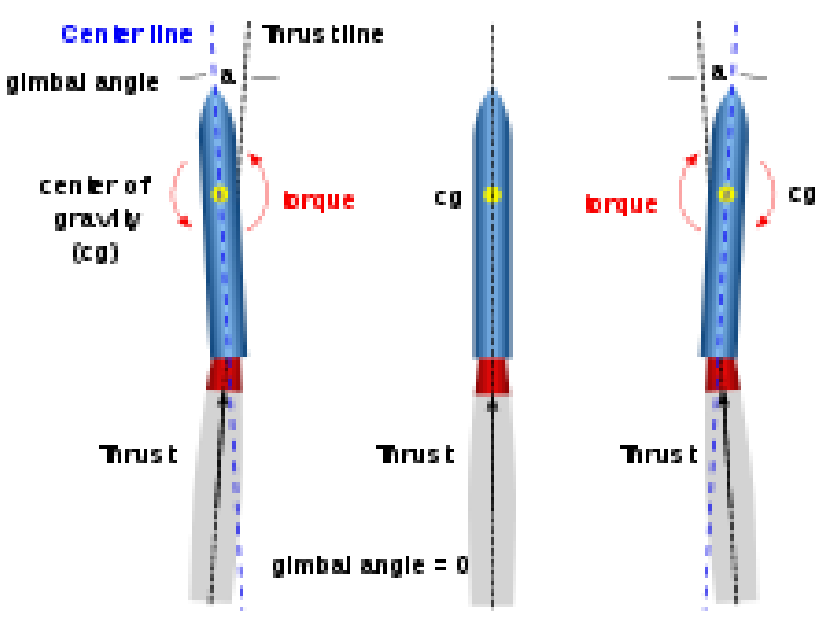

Our modification includes:

In order to employ it to work underwater actuation in only one axis is required, so a servo motor controlled using onboard microcontroller and operating under the command of data coming from transmitter, controls the thrust vectoring cylinder.

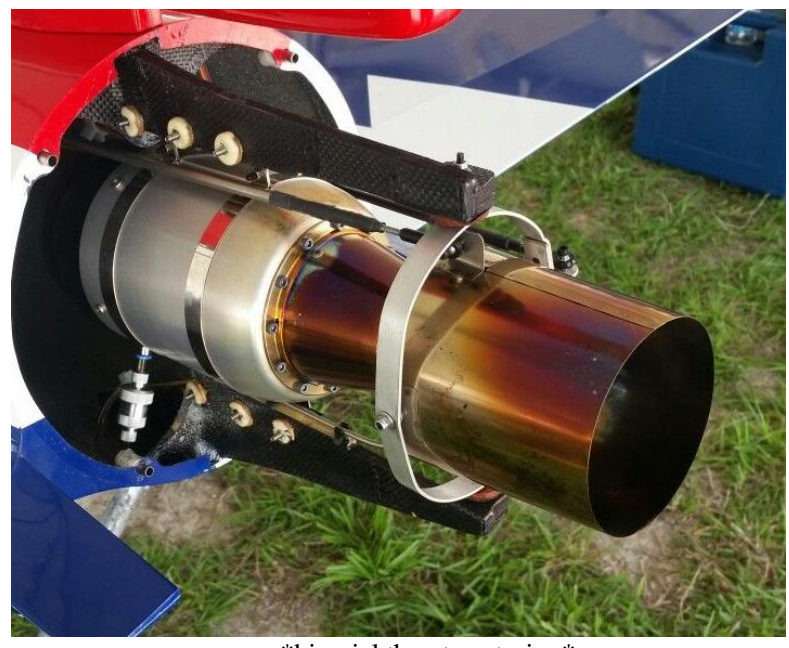

*bi-axial thrust vectoring*

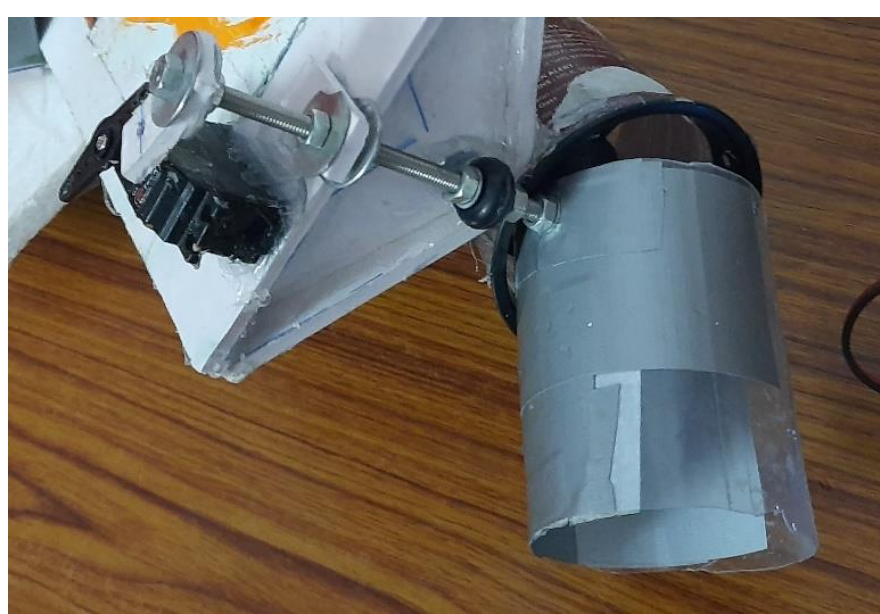

(OLD test system)

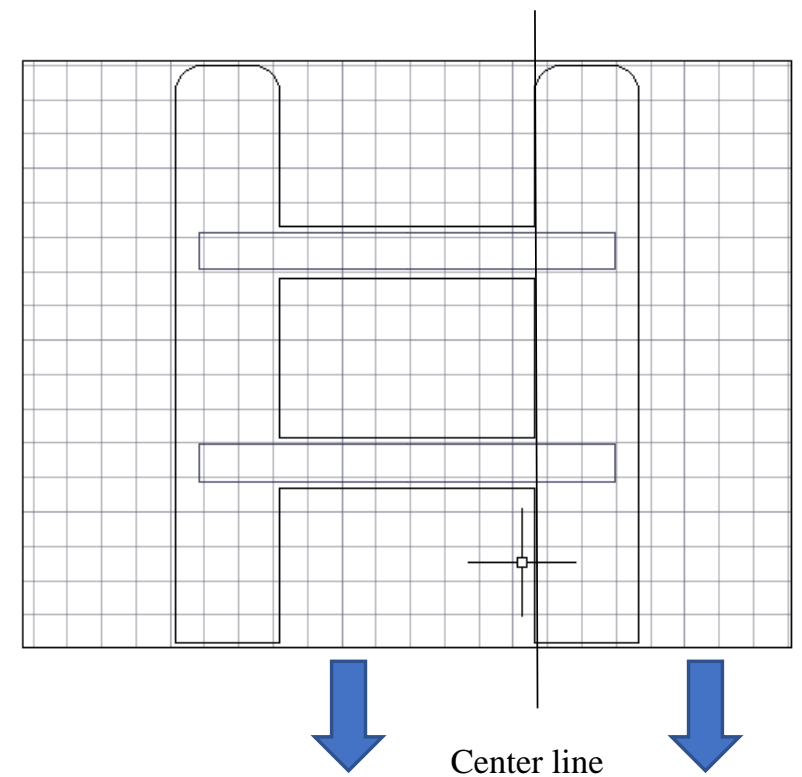

Propulsion EDF 1

Propulsion EDF 2

Above drawing is the representation of final prototype model. Instead of going with conventional one body one propulsion EDF system we went for Two propulsion EDF system to increase power. This was a necessary step as our field test confirmed the need of more power.

Turning principle here works on almost same principle as of thrust vectoring, it is called "varying thrust". As the name suggest by varying the thrust of EDF1 and EDF2, body of the drone will rotate about its center line.

for elaboration, if:

Right EDF increase the thrust whole drone will turn Right

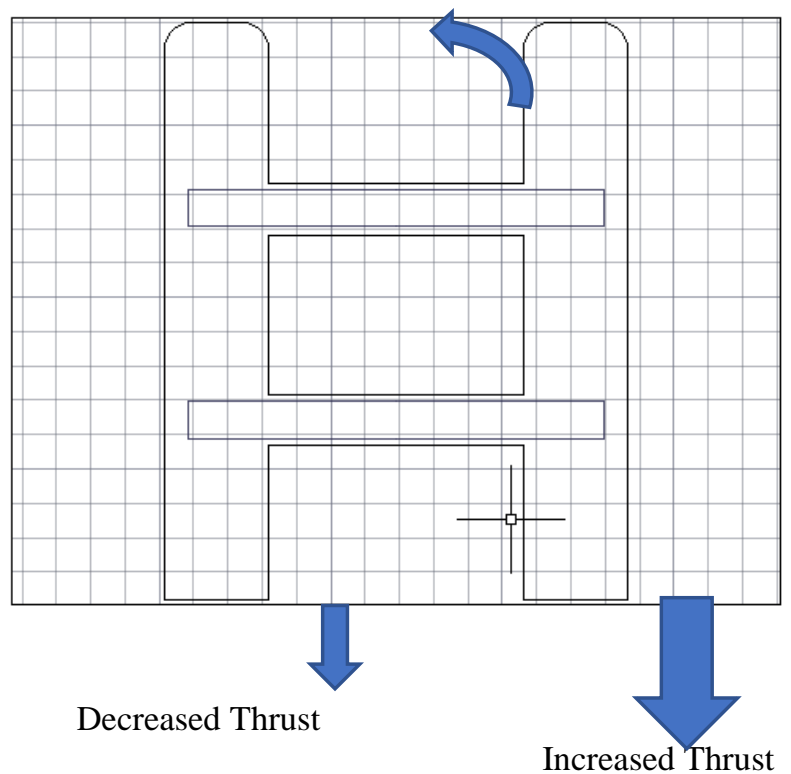

This concept is similar to the differential thrust system in aircraft, accept in this case since we can also reverse the direction of motor, this becomes convenient for very sharp turns. One motor with reverse thrust and one with forward thrust make the drone rotate on spot, much like a tank.

Fig 5. *Single axis thrust vectoring for TRV* 
Waste collection belt:

This specially designed conveyor belt is mounted between pontoons @ 15 to 20 degrees angle (Fig 6).

Two sets of gears connected with chain links are mechanically connected to each other using aluminum channel and steel rods. Steel rods are used to connect adjacent gears to each other (Fig 9), while aluminum channel connects the two rods with end mounted gears as shown in Fig 7, also this aluminum channel tightens the chain for proper functioning and preventing slip.

Left and right running chains are connected together with the help of steel rods $(\sim 5-8 \mathrm{~mm})$ in diameter which acts as the moving platform to transfer trash from water to storage area onboard.

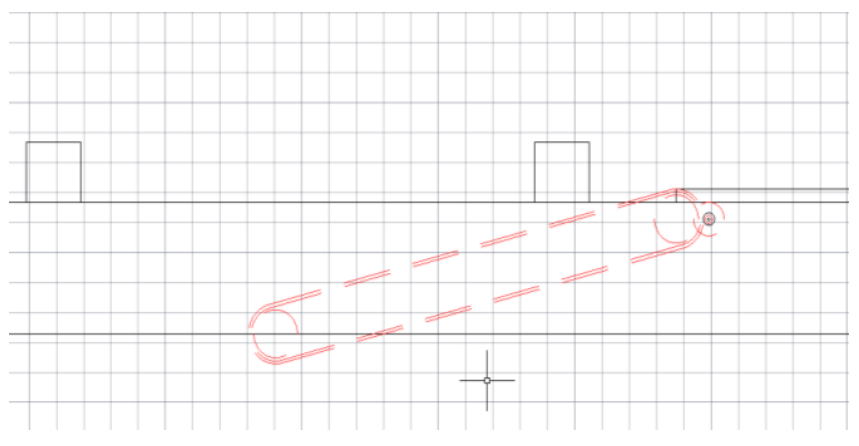

Fig 6. *AutoCAD illustration of mounting*

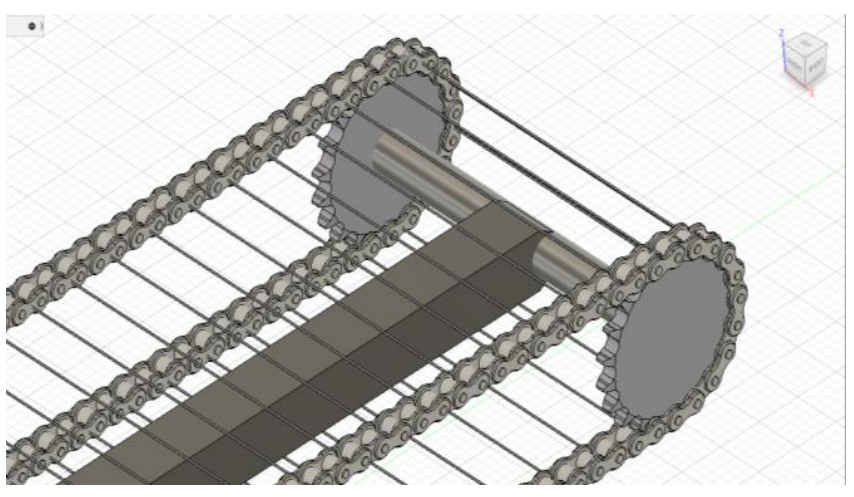

Fig7. *Full assembly of system*

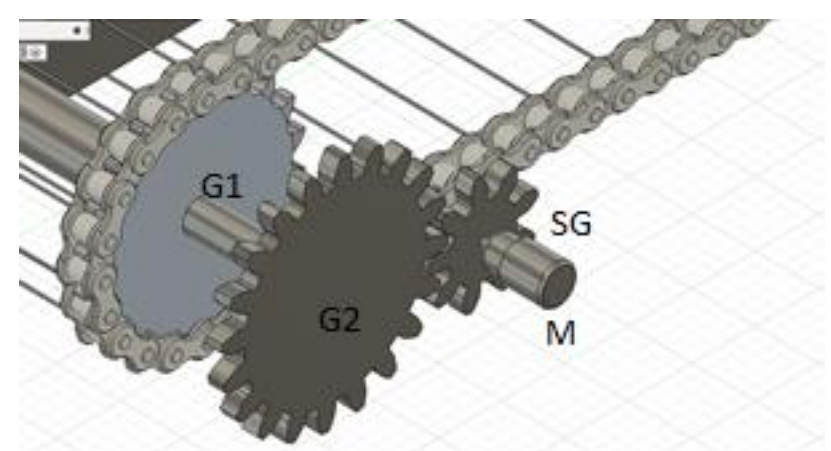

Fig 8. *Connection of drive mechanism*

As shown in Fig 8 one side of the main gear (G1) is connected to same size gear(G2) via steel rod. G2 is in mesh with SG (secondary gear) and SG is connected directly to a Geared DC motor having High torque @ 50RPM.
This DC motor is connected to the battery via $\mathrm{H}$ Bridge circuit that can reverse the polarity of motor in order to reverse the direction of rotation if need be. Powering ON/OFF the motor is decided by Arduino microprocessor that works on the command of user. Arduino microcontroller send signal to a relay that can turn ON/OFF the motor.

Testing notes:

- WD40 coating for waterproofing and gracing all the mechanical components

- Bearings in all the gear assembly

- $\quad$ Proper 3D printed platform to mount motor and gear mesh assembly

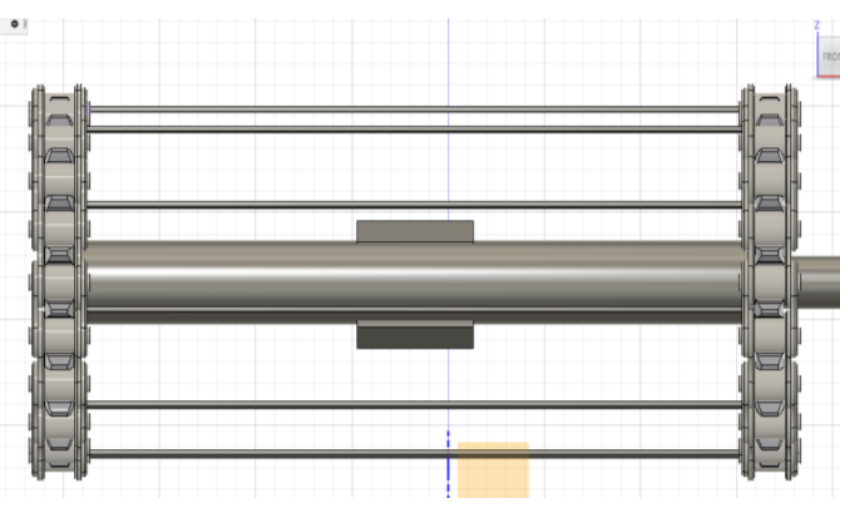

Fig 9. *Front view*

NOTE: all the parts are designed and tested in Solidworks/Autodesk Fusion 360

Table 1: Gear Data-

\begin{tabular}{|l|l|}
\hline \multicolumn{1}{|c|}{ Parameters } & \multicolumn{1}{c|}{ Values } \\
\hline Pressure angle & 20 \\
\hline Module & 8.1 \\
\hline Number of teeth & 20 \\
\hline Root fillet Radius & $1.588 \mathrm{~mm}$ \\
\hline Pitch diameter & $162 \mathrm{~mm}$ (calculated) \\
\hline
\end{tabular}

Environment mapping system: As stated earlier this drone have semi-autonomous capabilities, that is to say that it cannot drive itself but can assist the user by informing about the drone's immediate surrounding. so that user can make better decisions and double check if user missed something that can potentially harm the drone. 


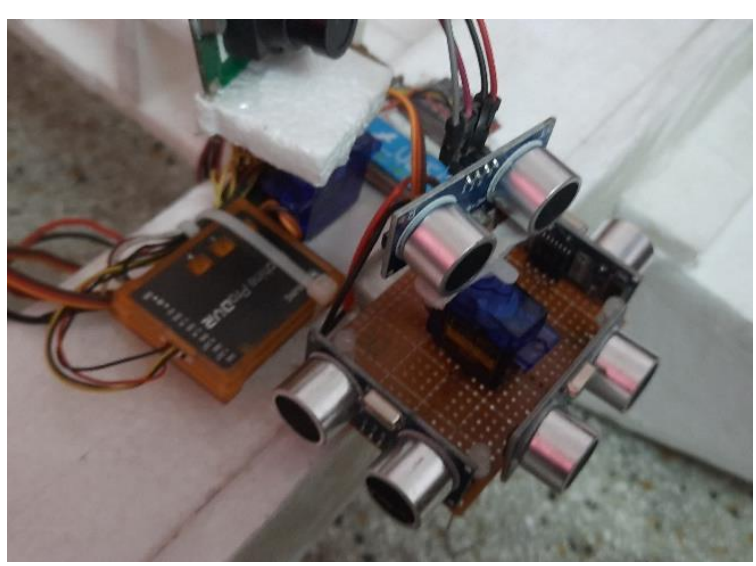

Fig 10. *Mounted and connected ultrasonic module*

Working of this system include 6 ultrasonic sensors.

- 3 sensors facing forward, left and right respectively.

- 2 sensors facing forward-right and Forward-left respectively.

- 1 sensor on servo motor.

Ultrasonic sensor has a measuring arc of (12 to 15 degrees) so, 5 sensors are statically placed and map the immediate environment.

When any one sensor detects something steadily moving towards the drone it informs the Arduino which in turn signals the servo mounted ultrasonic sensor to scan and track the said object. Also, Arduino warn the user using onboard NRF transceiver module.

\section{III.ELECTRONIC MODULES USED}

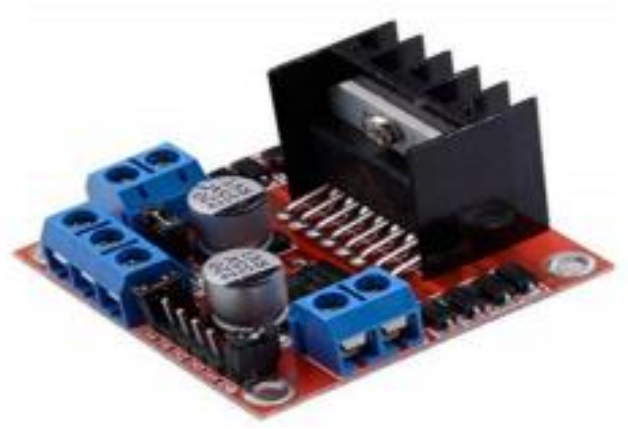

L298N Dual H-Bridge motor driver: The motor driver is electronic IC which is used for controlling the operations of motor like starting and stopping function of motor, for detecting the faults in motor, and other parameters which can affect the condition of motor

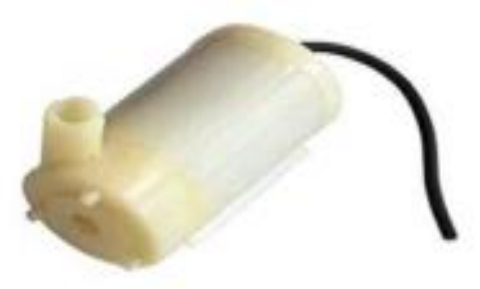

Submersible Pump: The submersible pump is associated with the rotor for cooling the electronics by pumping water in water blocks of temperature sensitive hardware that include ESC, Battery and Video transmitter. The submersible pump is connected with hull of the boat and operates on $5 \mathrm{~V}$ DC power for smooth functioning.

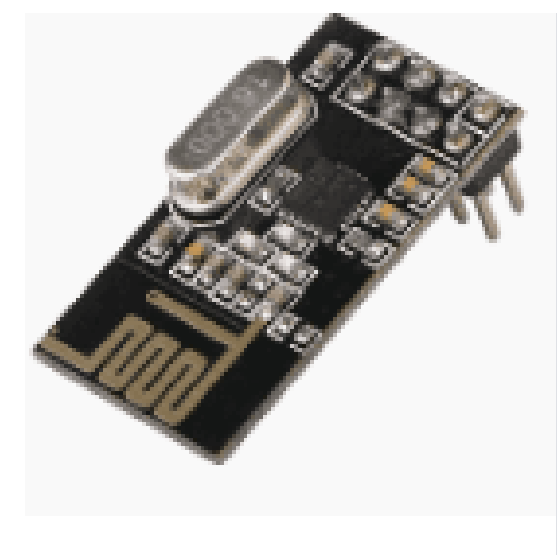

nRF24L01 is a single chip radio transceiver for the world wide $2.4-2.5 \mathrm{GHz}$ ISM band. The transceiver consists of a fully integrated frequency synthesizer, a power amplifier, a crystal oscillator, a demodulator\& modulator. The nRF24L01 is used on a wide variety of applications that require wireless control. They are transceivers which this means that each module can transmit and receive data.

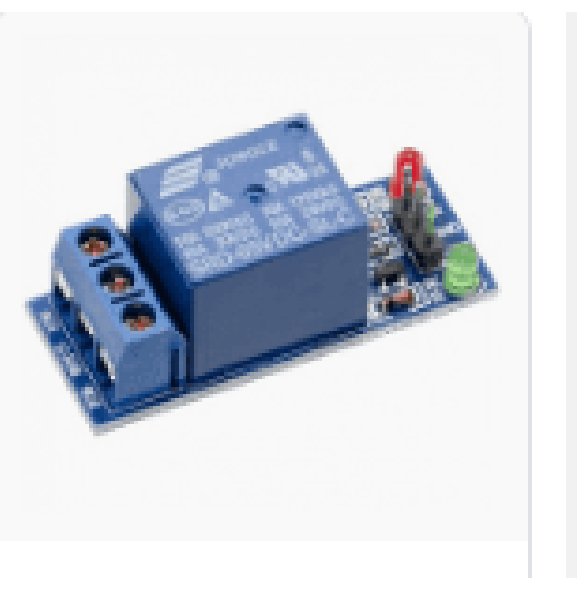

Relay: To control high-voltage or high-power circuits with an Arduino, we have to isolate them from the Arduino with a relay. Circuits that operate at high voltages or at high currents cannot be controlled directly by an Arduino. Instead, you use a low-voltage control signal from the 
Arduino to control a relay, which is capable of handling and switching high-voltage or high-power circuits. A relay consists of an electromagnet that, when energized, causes a switch to close or open. Relays provide complete electrical isolation between the control circuit and the circuit being controlled.

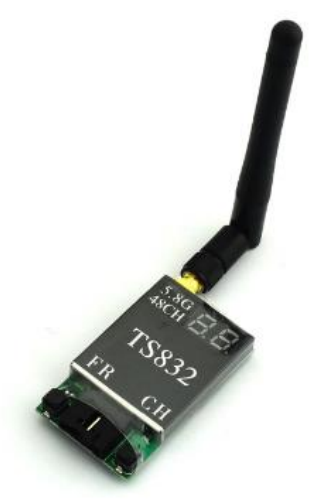

TS832 48Ch 5.8G 600mw Wireless Audio/Video Transmitter for FPV RC transmitter which will gives more than a $5 \mathrm{~km}$ range in an open, clear area.

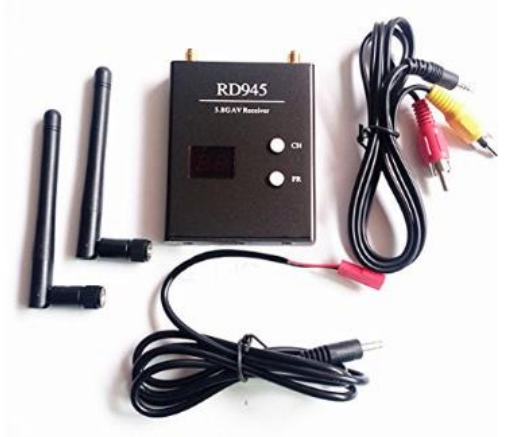

The RD945 FPV Wireless 5.8GHZ 48CH Receiver is a 48 channel $5.8 \mathrm{ghz}$ diversity receiver

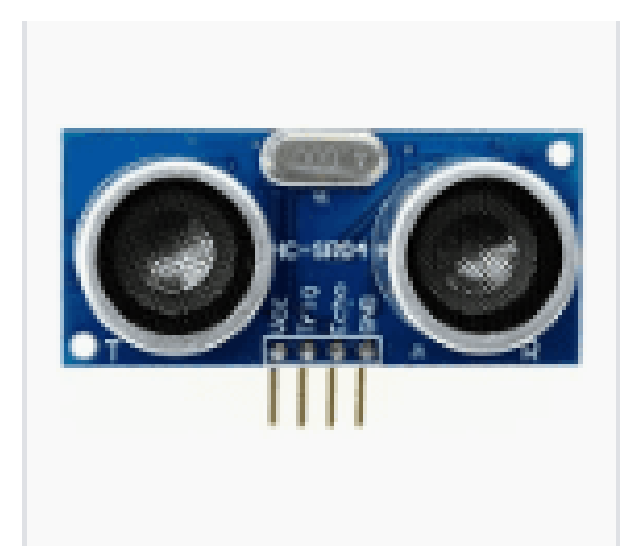

An ultrasonic sensor is an electronic device that measures the distance of a target object by emitting ultrasonic sound waves, and converts the reflected sound into an electrical signal. Ultrasonic waves travel faster than the speed of audible sound (i.e. the sound that humans can hear).
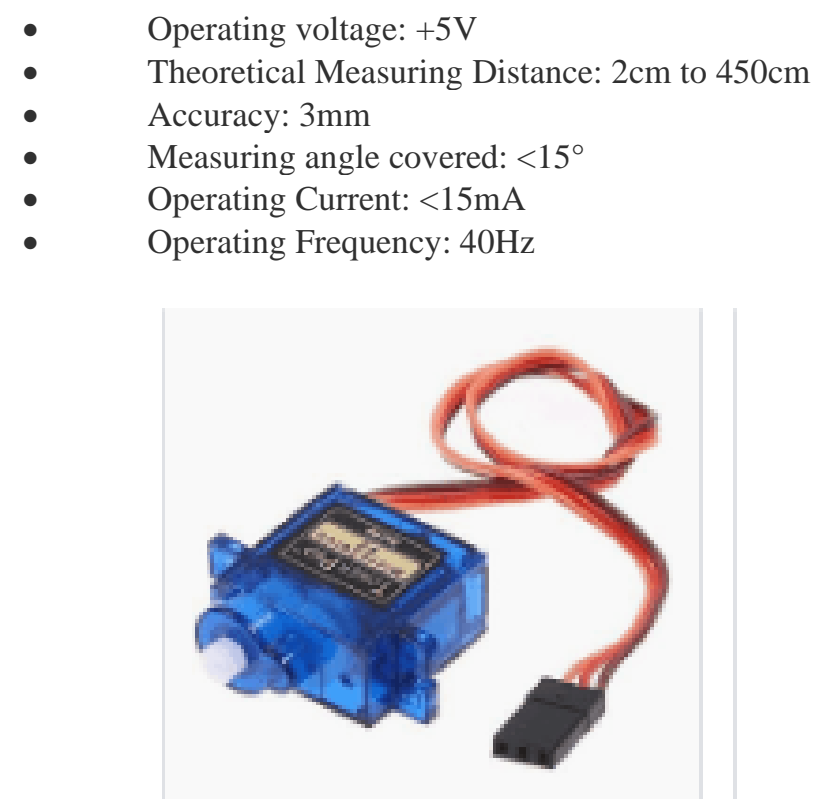

A servo motor is an electrical device which can push or rotate an object with great precision. If you want to rotate and object at some specific angles or distance, then you use servo motor. It is just made up of simple motor which run through servo mechanism.

\section{IV.WORKING OF DRONE}

Power on/standby phase: in this phase main switch on the drone is turned ON and RGB led surrounding the ultrasonic sensors turn RED.

Also, since connection to the battery is established Arduino microcontroller is powered on and start flashing GREEN LED on the board to indicate "initialization" or loading of the program. Once the program is loaded RGB LED turns solid GREEN to indicate that semi-autonomous feature is operational and transmitting data. RC $2.4 \mathrm{GHZ}$ receiver and video transmitter along with camera powers on to transmit live video.

Connection phase: $\mathrm{RC} 2.4 \mathrm{GHz}$ transmitter is powered on and pairs with receiver on the drone, same thing happens with the video receiver station. Once the video receiver station is powered on, we have to switch channels to find out which channel is being broadcasted upon by the video transmitter on the drone, said channel is locked upon to get constant and clear video feed.

Final checks phase: conveyor belt is powered on by the user, attached humanoid arm is checked and tested before launch, pump is switched on in order to start the watercooling system and various utility lights are switched on depending upon need. 

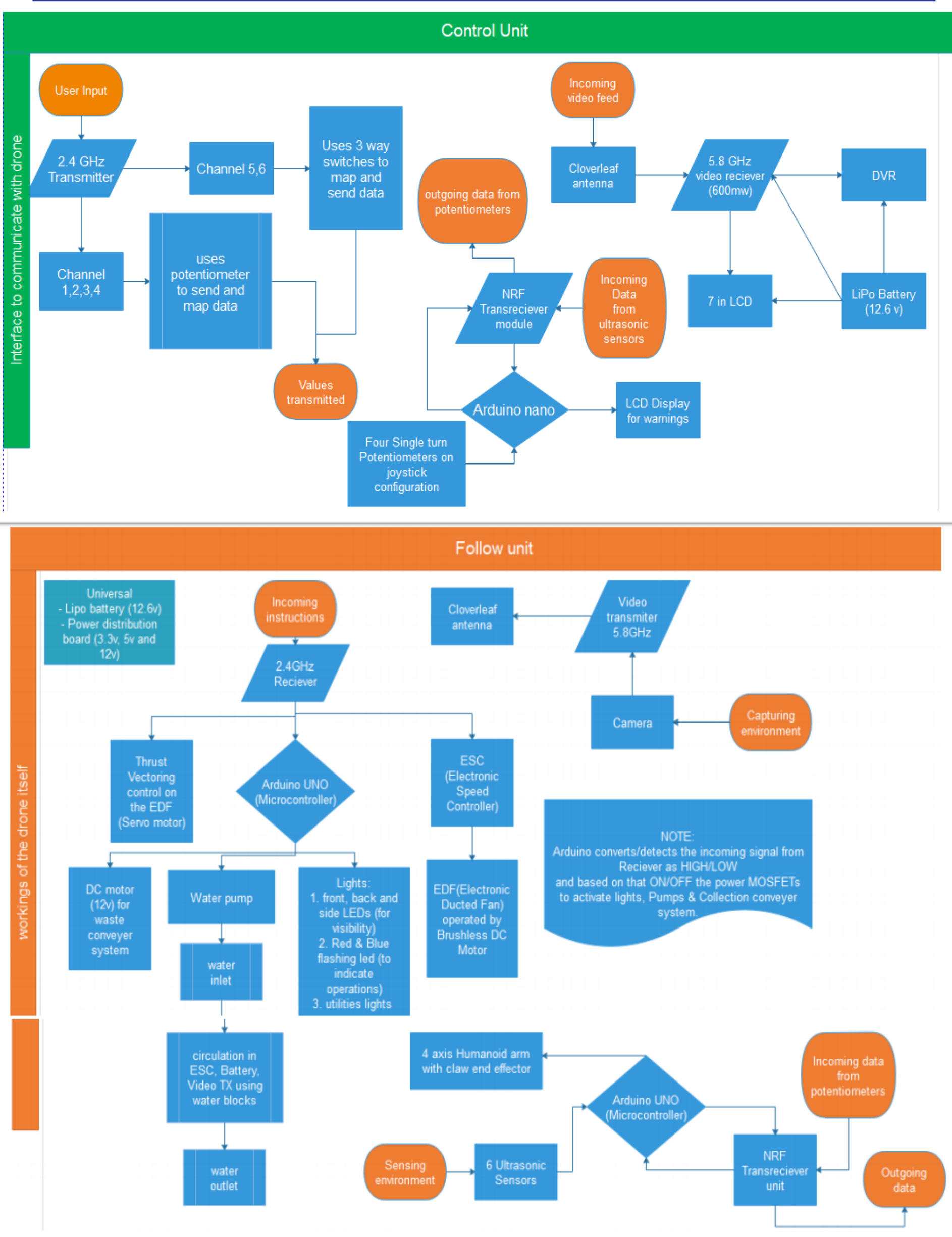
"Control unit" is the station controlled by the user in order to control the drone. It basically consists of three parts

- $2.4 \mathrm{GHz}$ transmitter in order to send signals to the drone controlling its movement in water

- Video receiving and display (on LCD)

- NRF transceiver module controlled using Arduino microcontroller to receive surrounding data and transmit arm orientation data.

"Follow Unit" is the flow diagrams for all the mounted electronics on the drone.

\section{V.RESULTS}

Table 2: Whole project was done in 7 iterations-

\begin{tabular}{|c|c|c|}
\hline Iteration & Changes made & Impact on final design \\
\hline Mark 1 & $\begin{array}{l}\text {-Design involved one long duct } \\
\text { with EDF in center mounted in the } \\
\text { boat @ } \\
30-40 \text { degrees. It utilized air to } \\
\text { propel the boat }\end{array}$ & $\begin{array}{l}\text { Idea was to save the } \\
\text { electronics from water } \\
\text { and have fewer moving } \\
\text { parts inside water. } \\
\text { (Failed due to horrible } \\
\text { efficiency and loss of } \\
\text { power) }\end{array}$ \\
\hline Mark 2 & $\begin{array}{l}\text {-Design involved main boat } \\
\text { structure supported by two } \\
\text { pontoons to direct and collect the } \\
\text { trash. } \\
\text { - EDF was mounted beneath the } \\
\text { hull(submerged) } \\
\text {-Thrust vectoring to turn the drone } \\
\text { was also implemented at this stage. }\end{array}$ & $\begin{array}{l}\text { Idea was to check } \\
\text { stability and feasibility of } \\
\text { the design (Failed due to } \\
\text { idea of a better design) } \\
\text {-large amount of surface } \\
\text { area in water was } \\
\text { increasing DRAG }\end{array}$ \\
\hline Mark 3 & $\begin{array}{l}\text { After figuring out the suitable } \\
\text { propulsion in Mark } 1 \& 2 \text {, this } \\
\text { iteration focused on electronics and } \\
\text { mountings. } \\
\text {-FPV camera system was mounted } \\
\text { and tested } \\
\text {-Arduino microcontroller along } \\
\text { with NRF module was also } \\
\text { mounted first }\end{array}$ & $\begin{array}{l}\text { All systems worked great } \\
\text { and with ease, although } \\
\text { overheating in Battery } \\
\text { and video transmitter was } \\
\text { observed due to } \\
\text { occasional current boost } \\
\text { and constant running } \\
\text { respectively. }\end{array}$ \\
\hline Mark 4 & $\begin{array}{l}\text { Water cooling system and utility } \\
\text { lights was first implemented (front, } \\
\text { back and working lights) }\end{array}$ & $\begin{array}{l}\text { A pump took water from } \\
\text { testing grounds and } \\
\text { pumped it through water } \\
\text { blocks attached to ESC, } \\
\text { Battery and video } \\
\text { transmitter. This } \\
\text { completely solved the } \\
\text { heating issue and imp- } \\
\text { roved the life as well as } \\
\text { safety factor of the } \\
\text { electronics. }\end{array}$ \\
\hline Mark 5 & $\begin{array}{l}\text { At this point we observed how } \\
\text { inefficient and difficult to work } \\
\text { with our current design was so, } \\
\text { main body of the drone was } \\
\text { completely redesigned from main } \\
\text { body surrounded by pontoons to } \\
\text { two connected pontoons. }\end{array}$ & $\begin{array}{l}\text { This not only increased } \\
\text { the efficiency } \\
\text { considerable but thrust } \\
\text { vectoring concept to turn } \\
\text { the drone was scrapped } \\
\text { on this stage due to the } \\
\text { dual EDF configuration } \\
\text { we utilized the concept of } \\
\text { differential thrust. }\end{array}$ \\
\hline Mark 6 & $\begin{array}{l}\text { Almost all of the electronics except } \\
\text { trash collecting conveyor belt was } \\
\text { mounted at this point and once } \\
\text { again the field testing was done }\end{array}$ & $\begin{array}{l}\text { Humanoid arm proved } \\
\text { useful, although a little } \\
\text { slow due to all the traffic } \\
\text { on one NRF module. }\end{array}$ \\
\hline
\end{tabular}

\begin{tabular}{|l|l|l|}
\hline Mark 7 & Final assemble done and tested & -Very high efficiency \\
based on various factors \\
like, payload capacity, \\
power and its \\
& & $\begin{array}{l}\text { distribution, } \\
\text { responsiveness and } \\
\text { operational time } \\
\end{array}$ \\
& -Although sometimes \\
& stuck, conveyor belt \\
& works with the efficiency \\
& of 88\% (tested in 3hr of \\
& operation) \\
& - drone did not got stuck \\
& once in 3hr operation due \\
& to our various design \\
& measures. \\
\hline
\end{tabular}

\section{VI.CONCLUSIONS}

The device worked as designed and planned, the user easily controlled the device and cleaned the surrounding efficiently. One of the main purposes of this machine was to be practical and utilize rare mechanisms/theories to increase the learning factor, which is fulfilled. There was a lot of learning involved going through various iterations mark 1 to mark 7 in development process.

One of the main features is that, this machine can support many more different accessories like GPS, Telemetry, Liion battery system etc to improve its functionality and increase user friendliness.

\section{VII.REFERENCES}

[1] Website for Arduino code libraries and it's implementations "https://www.arduino.cc/"

[2] Andy Lennon "The basics of R/C model aircraft design" by air age media Inc., 100 east ridge, Ridgefield, CT (1996), (reference)

[3] Patrick C.Vratny, Mirko Hornung "Sizing Considerations of an Electric Ducted Fan for Hybrid Energy Aircraft"

[4] Website for data and theory study "https://en.wikipedia.org/wiki/Ducted fan".

[5] Implementation and conversion of EDF into modified waterjet "https://www.hamiltonjet.com/global/waterjet-overview"

[6] Yongseon Moon, Nak Yong $\mathrm{Ko}$ and Youngchul Bae "https://www.intechopen.com/books/humanoid_robots/the_desi gn_of_humanoid_robot_arm based on morphological_and_ne urological_analysis_of_human_arm” Published: January $1 \mathrm{st}$ 2009, DOI: $10.5772 / 6730$

[7] Website for introduction and implementation of thrust vectoring "https://en.wikipedia.org/wiki/Thrust_vectoring"

[8] NASA website for calculations involved with thrust vectoring "https://www.grc.nasa.gov/WWW/K-12/airplane/vecthrst.html"

[9] Zachary J. Merceruio West Virginia University "Modeling and flight testing of differential thrust and thrust vectoring on a small UAV" 2011 Link

https://researchrepository.wvu.edu/cgi/viewcontent.cgi?article $=1$ $294 \&$ context $=$ et

[10] Website for basics and implementation of differential mechanism "https://www.flitetest.com/articles/how-to-program-differentialthrust\#: :text=Differential\%20thrust\%20is\%20used\%20for,to\% 20 give $\% 20$ better $\% 20$ yaw $\% 20$ authority.\&text $=$ To $\% 20$ program $\% 20$ differential $\% 20$ thrust $\% 2 \mathrm{C} \% 20$ you,right $\% 20$ motor $\% 20$ into \%20channel\%206."

[11] R.S. Khurmi (Author) " A textbook for Machine Design" publication - S Chand, 2005 (For designing and 3d printing)

[12] K. Mahadevan, K. Balaveera Reddy "Design Data Handbook", publication - CBS, 2019 (For designing and 3d printing)

[13] Website for ultrasonic sensor datasheet "https://components101.com/ultrasonic-sensor-working-pinoutdatasheet"

[14] Website for learning and implementation of servo motors "https://en.wikipedia.org/wiki/Servomotor" 


\section{SOFTWARE USED:}

1. Auto CAD

2. Autodesk Fusion 360

3. Autodesk Solidworks

4. $\quad$ Flowchart maker 8 (illustrations)

5. Arduino IDE (Coding)

6. MS office (preparing) 